ally required. Sorting and microfilming is likely to be too time-consuming to be profitable.

It it is impossible for hospitals to preserve case notes for a useful period of time could not some central storage depot be instituted in each region or area, where old medical records would be available to any hospital?

It is a depressing thought that as fast as one is making careful and detailed clinical notes during one year, a "medical records destruction officer" is steadily tearing them up a few years later.-I am, etc.,

ERIC C. O. JEWESBURY

London $\mathbf{W} .1$

\section{Preclinical Salaries}

SIR,-With reference to Professor G. R. Kelman's letter (28 August, p. 537) querying my statement that there is a $5 \%$ differential between the preclinical and clinical salaries, I was in error. He is correct, and I am glad he has given some concrete examples of the great disparity between clinical and preclinical salaries. I must confess that my $5 \%$ differential was quoted from memory of official B.M.A. policy, which was declared in their submission to the National Board for Prices and Incomes (1969), and which argued that medically qualified teachers should receive at least $90 \%$ of that received by their clinical colleagues.

I would point out that at the recent A.R.M. at Leicester the motion that ". . . all medical graduates employed in university preclinical and clinical departments should be on the same salary scale" was carried (Supplement, 31 July, p. 76).

It would seem from the evidence which has already been given in your correspondence columns that the differential is greater than the declared official policy of the B.M.A. This makes me more convinced than ever that a policy of no differentials between the salaries of clinical and preclinical disciplines should be adopted by the B.M.A., the Universities, and the Association of University Teachers in order to halt the deterioration in the present position and to aid recruitment in the future.-I am, etc.,

Pathology Unit,

Royal Free Hospital,

KENNETH R. HIIL

London W.C.1

\section{Hospital Staff Appointments}

SIR,-It is high time that the correspondence on this subject was brought back to my original thesis, judging by your latest correspondents (11 September, p. 638) who, along with others who have equally sought to misuse its purpose in order to ventilate their grievances against appointing committees, have forgotten (or never realized) the simple point of my inaugural letter (22 May, p. 470). In effect, this stated that having finally decided to accept an appointment, a candidate must honour that acceptancevoluntarily, or otherwise.

While I naturally sympathize with sufferers from unpleasant experiences while seeking hospital staff appointments (and I myself have been far from immune from such ex- periences) I submit that the correction of such malpractice must be the subject of an entirely different investigation.-I am, etc.,

East Glamorgan General Hospital,
Glam

J. DE SWIET

\section{Sauce, Spices, and the Kidney}

SIR,-I agree with your leading article (3 July, p. 6) that the number of people who take sufficient Worcestershire sauce to cause kidney damage must be small. But, when I reported the association of excess sauce and kidney stones ${ }^{1}$ or general renal failure; ${ }^{2}$ I had in mind the potential implications in people who habitually take similar spices in large amounts. The countries with very high incidence of renal tract stones include parts of India and Mexico, ${ }^{3}$ where curry and other hot spices are very popular. If these condiments can be shown to be contributing to the kidney troubles, the number of people potentially involved is very great.

I have found that most visitors from India, when offered the suggestion that curry could be a factor in their country's renal problems, react as if a national institution has been maligned. It was therefore very gratifying to note the observation by Mr. G. Holmes (24 July, p. 252) that kidney stones are very common in Fijian Indians, and scarcely ever occur in Fijians, and that the difference could be due to "curry kidney." - I am, etc.,

\section{Princess Alexandra Hospital,}

K. J. MURPHY

Woolloongabba, Brisbane,
Queensland, Australia

1 Murphy, K. J., Lancet, 1967, 2, 401. 1, 1119 .

Straffon, R. A., and Higgins, C. C., in Urology,
ed. M. F. Campbell and J. H. Harrison, 3rd edn. W. B. Saunders Co., London, 1970, Vol. I, p. 688 .

\section{"Clinical" and "Administrative" Pharmacists}

SIR,-It is encouraging to read letters expressing apprehension at the currently held idea that the normal promotional ladder of any profession rises naturally beyond the technical field to that of administration and management.

The Health Service is concerned with the patient as an individual and the closer one works to the patient the more exacting, specialized, and demanding the work becomes. The medical profession realized this and accepted the Cogwheel system ${ }^{1}$ as a method of self administration. At the same time it is normal to achieve professional eminence as a doctor without having of necessity to become an administrator.

Your correspondents suggest that there is a defect in the Salmon report inasmuch as a nurse can only rise up the promotional ladder by "defecting" to the administrative field. As a hospital pharmacist may I suggest that precisely the same "blind spot" appears in the Noel Hall report for the reorganization of hospital pharmacy. ${ }^{2}$ At the head of the financial scale, and possessing executive power, is the regional pharmacist. Next below him is the area pharmacist controlling some 6,000 beds-probably some three or four existing groups. He is to have power of deployment of the area pharma- ceutical forces, and his will be an administrative job.

The individual pharmacist working in a hospital may not have the authority or professional freedom which would place him on a professional level with the senior medical and nursing officers in his own hospital. Nor can he rise to any career salary level. If a "clinical" pharmacist wishes to make a promotional career he will have to desert working pharmacy for administration following the latest god of managerial efficiency.

Since the publication of these various reports there has developed some feeling that undue emphasis has been placed on the preeminence of managerial and administrative functions in professions which are basically concerned with scientific technicalities, and it is to be hoped that notice will be taken of these views to redirect the balance of change. -I am, etc.

J. FOGG

Royal Alexandra Hospital,

Rhyl

1 Organization of Medical Work in Hospitals. London, H.M.S.O., 1967

Department of Health and Social Security. Scottish Home and Health Department. Welsh Office. Report of the Working Party on the Hospital
Pharmaceutical Service. London, H.M.S.O., 1970.

\section{Cremation Regulations}

SIR,-I should like to preface what follows by the emphatic statement that this is not intended as a criticism of Her Majesty's coroners, who, in my experience, perform a difficult task with skill and tact.

I am a referee of the Norwich Crematorium Limited, and in this capacity it is one of my duties to countersign Form F of the Application for Cremation form in cases which have been reported to the coroner and a postmortem has been held because the general practitioner or hospital doctor has been unable to sign the death certificate. I am provided with certain sections of the Application for Cremation form which are Form A (which is an application for cremation), the coroner's Certificate E, in which the coroner expresses his satisfaction that cremation may go forward, and Form F, which I am required to sign as the final authority to cremate. In Form F, it states that "I have satisfied myself that all the requirements of the Cremation Acts, 1902 and 1952, and of the Regulations made in pursuance of those Acts, have been complied with, that the cause of death has been definitely ascertained, and that there exists no reason for any further inquiry or examination."

Obviously I do not doubt the coroner's word, but I am expected to sign this form without having any knowledge of the cause of death. This has led me to correspond with the Home Office, which has been most helpful in answering my queries, and from which I gather that the changes introduced by the Cremation Regulations of 1965 were discussed with the B.M.A., the Home Office, and the Coroner's Society of England and Wales Committee. May I quote two relevant points from the letter written to me by a Home Office official?

"The purpose of Regulation 1 of these new Regulations was to remove the prohibition of Cremation, which formerly existed, in those cases in which an inquest had been opened, but not completed, although all the 